INFLAMMATORY BOWEL DISEASE

\title{
Combined oral and enema treatment with Pentasa (mesalazine) is superior to oral therapy alone in patients with extensive mild/moderate active ulcerative colitis: a randomised, double blind, placebo controlled study
}

\author{
P Marteau, C S Probert, S Lindgren, M Gassul, T G Tan, A Dignass, R Befrits, G Midhagen, \\ J Rademaker, M Foldager
}

Gut 2005;54:960-965. doi: 10.1136/gut.2004.060103

See end of article for authors' affiliations

....................

Correspondence to: Professor P Marteau, Gastroenterology, Hopital Européen Georges Pompidou, 20 rue Leblanc, 75908 Paris cedex 15,

France;

philippe.marteau@

hop.egp.ap-hop-paris.fr

Revised version received 24 January 2005

Accepted for publication

25 January 2005
Background and aims: Oral aminosalicylates are well established in the treatment of active mild/ moderate ulcerative colitis (UC) when the disease is extensive (that is, beyond the splenic flexure). The majority of clinical symptoms relate to disease activity in the distal part of the colon and therefore this study was designed to investigate if adding a mesalazine enema to oral mesalazine has additional benefit for patients with extensive mild/moderate active UC.

Methods: A randomised double blind study was performed in 127 ambulatory patients. All received $4 \mathrm{~g} /$ day (twice daily dosing) oral mesalazine for eight weeks. During the initial four weeks, they additionally received an enema at bedtime containing $1 \mathrm{~g}$ of mesalazine or placebo. Disease activity was assessed using the ulcerative colitis disease activity index, with clinical and endoscopic signs at four and eight weeks.

Results: Remission was obtained in $44 \%$ (95\% confidence interval (CI) $31 \%, 58 \%$ ) of the mesalazine enema group (Me) and in $34 \%(95 \% \mathrm{Cl} 21 \%, 49 \%)$ of the placebo enema group (PI) at four weeks $(\mathrm{p}=0.31)$ and in $64 \%(95 \% \mathrm{Cl} 50 \%, 76 \%)$ of the Me group versus $43 \%(95 \% \mathrm{Cl} 28 \%, 58 \%)$ of the $\mathrm{Pl}$ group at eight weeks $(p=0.03)$. Improvement was obtained in $89 \%(95 \% \mathrm{Cl} 78 \%, 96 \%)$ of the Me group versus $62 \%(95 \% \mathrm{Cl}$ $46 \%, 75 \%)$ of the $\mathrm{Pl}$ group at four weeks ( $\mathrm{p}=0.0008)$ and in $86 \%(95 \% \mathrm{Cl} 75 \%, 94 \%)$ of the Me group versus $68 \%(95 \% \mathrm{Cl} 53 \%, 81 \%)$ of the $\mathrm{Pl}$ group at eight weeks $(\mathrm{p}=0.026)$.

Conclusion: In patients with extensive mild/moderate active UC, the combination therapy is superior to oral therapy. It is safe, well accepted, and may be regarded as firstline treatment.

\section{A} minosalicylates are the mainstay of therapy in mild to moderately active ulcerative colitis (UC) but optimisation of therapy is needed. ${ }^{12}$ Mesalazine, both oral and topical (enema, foam, and suppositories), has been shown to be effective-either alone or in combination with oral or rectal administration-for treating active UC, as well as in maintaining remission..$^{2-7}$ Distal forms of the disease can be effectively treated topically (enemas, foams, or suppositories), orally, or with a combination of both. Randomised controlled trials performed in patients with distal UC showed that local treatments are more rapidly effective than oral treatment, ${ }^{7}$ and that a combination of local and oral therapy was more effective. ${ }^{8}$ The optimal dose of 5 -aminosalicylic acid (5-ASA) as firstline treatment for distal disease has been found to be $1 \mathrm{~g} /$ day rectally. ${ }^{7-10}$ The combination therapy of enema twice weekly in addition to oral treatment $1.6 \mathrm{~g} /$ day was also found to be more effective in maintaining remission than oral treatment alone. ${ }^{311}$ Frieri and colleagues ${ }^{12}$ observed significantly higher concentrations of 5-ASA in distal colonic mucosa when adding an enema to oral therapy. Naganuma and colleagues ${ }^{13}$ presented similar results, supporting the idea that an oral/enema combination therapy would be beneficial to patients.

As suppositories do not have a topical effect above the rectosigmoid junction and as $100 \mathrm{ml}$ enemas are not spread above the splenic flexure, extensive UC (extending above the splenic flexure) requires oral treatment. This treatment is usually given alone and a daily dose of $4 \mathrm{~g}$ /day is considered optimal. ${ }^{12414}$ The majority of clinical symptoms in extensive UC probably relate to disease activity in the distal part of the colon. We speculated that combining an oral and enema therapy would decrease distal symptoms (bleeding, frequency of bowel movement) more effectively than oral therapy alone. Whether a combination therapy using optimal doses could be faster and/or more effective in inducing remission in patients with extensive acute UC has never been studied in a randomised placebo controlled trial. A previous study has shown that mesalazine $2 \mathrm{~g}$ orally plus $2 \mathrm{~g}$ enemas was not more effective than the usual $4 \mathrm{~g}$ oral treatment in inducing remission ${ }^{15}$ but the study included very few patients with extensive UC. Another earlier trial, comparing the efficacy of oral mesalazine $2.4 \mathrm{~g}$ /day with a daily 5-ASA enema given for either four or eight weeks, showed that an additional four weeks of topical treatment did not increase the remission rate. ${ }^{16}$

We report the results of a randomised, double blind, placebo controlled study examining whether adding $\mathrm{l} g$ mesalazine rectal enema in the initial four weeks of an eight week treatment regimen with oral mesalazine therapy $(4 \mathrm{~g})$ had any additional benefit for patients with extensive mild/ moderate UC.

Abbreviations: UC, ulcerative colitis; 5-ASA, 5-aminosalicylic acid; UCDAl, ulcerative colitis disease activity index; IT, intention to treat; PP, per protocol 


\begin{tabular}{|c|c|c|}
\hline & $\begin{array}{l}\text { Mesalazine enema } \\
(n=71)\end{array}$ & $\begin{array}{l}\text { Placebo enema } \\
(n=56)\end{array}$ \\
\hline Age (y) (median (range)) & $42(18-76)$ & $47(19-79)$ \\
\hline $\begin{array}{l}\text { Sex (male) (n (\%)) } \\
\text { Smoking habits (n (\%)) }\end{array}$ & $44(62 \%)$ & $32(57 \%)$ \\
\hline Non-smoker & $36(51 \%)$ & $27(48 \%)$ \\
\hline Ex-smoker & $27(38 \%)$ & $19(34 \%)$ \\
\hline Current smoker & $8(11 \%)$ & $10(18 \%)$ \\
\hline $\begin{array}{l}\text { Duration of UC (y) } \\
\text { (median (range)) }\end{array}$ & $4(0-35)$ & $8(0-39)$ \\
\hline$<1$ y (n (\%)) & $17(24 \%)$ & $8(14 \%)$ \\
\hline $1-10$ y (n (\%)) & $37(52 \%)$ & $28(50 \%)$ \\
\hline$>10$ y (n (\%)) & $17(24 \%)$ & $20(36 \%)$ \\
\hline
\end{tabular}

\section{PATIENTS AND METHODS}

\section{Patients}

Patients were recruited between January 2002 and July 2003 in six European countries (France, UK, Spain, Germany, the Netherlands, and Sweden). The study was approved by local institutional review boards and ethics committees. Male and female patients $>18$ years of age were eligible to participate if they had previously established extensive UC with mild to moderate exacerbation. The ulcerative colitis disease activity index (UCDAI) score had to be $\geqslant 3$ and $\leqslant 8 .{ }^{17}{ }^{18}$ All patients gave written informed consent prior to study entry. Exclusion criteria were: patients with infectious colitis; patients receiving oral maintenance treatment with total daily doses $>3 \mathrm{~g}$ of sulfasalazine, mesalazine, or 4-ASA within 30 days prior to study entry; any immunosuppressive agents during the 90 days prior to study enrolment; chronic use of nonsteroidal anti-inflammatory drugs (oral and/or rectal routes) in the seven days prior to inclusion (chronic use defined as drug intake for a minimum of seven consecutive days); intake of corticosteroids (oral and/or rectal routes) within

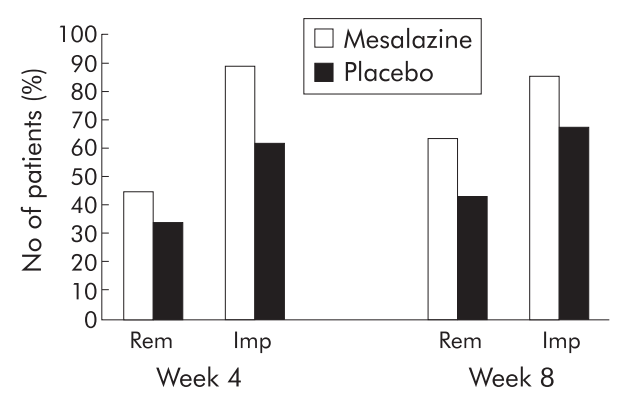

Figure 2 Remission and improvement rates. Percentage of patients achieving remission (ulcerative colitis disease activity index (UCDAI) of 0 or 1) or improvement (decrease in UCDAI >2 points). Rem, remission; Imp, improvement.

seven days prior to enrolment; severe renal/hepatic impairment, malignant disease, allergy to salicylates, alcoholism, or drug addiction, or any other disease or condition that might interfere with study assessments, as judged by the investigator; participation in another clinical study in the previous 30 days; women of child bearing potential who were not using an effective method of contraception; pregnancy, and lactation.

\section{Methods}

This was a double blind, multinational, randomised, parallel group, placebo controlled, eight week clinical study in outpatients with a previously established diagnosis of extensive mild/moderate UC (macroscopic inflammation beyond the splenic flexure during a full colonoscopy). For eight weeks each patient emptied two mesalazine $1 \mathrm{~g}$ sachets (Pentasa, Ferring, Denmark), twice daily, onto their tongue and swallowed with some water or juice. During the initial four weeks, each patient also applied daily a $100 \mathrm{ml}$ enema at

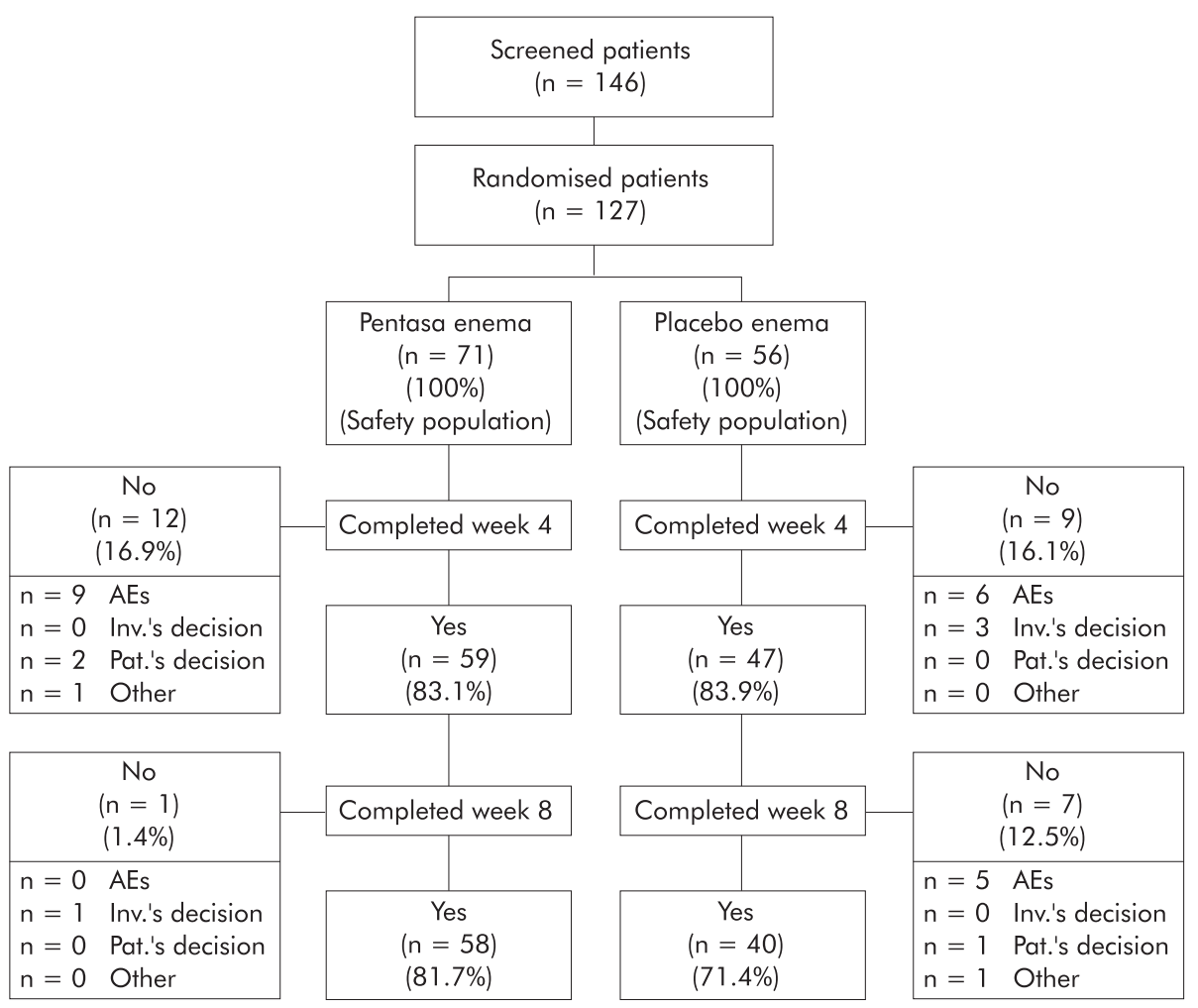

Figure 1 Flow chart describing the progress of patients during the course of the study. AEs, adverse events; Inv.'s decision, investigator's decision; Pat.'s decision, patient's decision. 
Table 2 Improvement rates in the intention to treat (ITT) and per protocol (PP) populations

\begin{tabular}{|c|c|c|c|c|c|c|c|c|}
\hline & \multicolumn{4}{|c|}{ ITT population } & \multicolumn{4}{|c|}{ PP population } \\
\hline & $\begin{array}{l}\text { Total No } \\
\text { of patients }\end{array}$ & $\begin{array}{l}\text { Improvement } \\
\text { rate (\%) }\end{array}$ & $95 \% \mathrm{Cl}$ & p Value & $\begin{array}{l}\text { Total No } \\
\text { of patients }\end{array}$ & $\begin{array}{l}\text { Improvement } \\
\text { rate (\%) }\end{array}$ & $95 \% \mathrm{Cl}$ & p Value \\
\hline \multicolumn{9}{|l|}{ Week 4} \\
\hline Mesalazine enema & 57 & 89 & $78 \%, 96 \%$ & \multirow{2}{*}{0.0008} & 41 & 88 & $74 \%, 96 \%$ & \multirow{2}{*}{0.0115} \\
\hline $\begin{array}{l}\text { Placebo enema } \\
\text { Week } 8\end{array}$ & 47 & 62 & $46 \%, 75 \%$ & & 29 & 62 & $42 \%, 79 \%$ & \\
\hline Mesalazine enema & 58 & 86 & $75 \%, 94 \%$ & \multirow{2}{*}{0.0256} & 42 & 88 & $74 \%, 96 \%$ & \multirow{2}{*}{0.0464} \\
\hline Placebo enema & 47 & 68 & $53 \%, 81 \%$ & & 29 & 69 & $49 \%, 85 \%$ & \\
\hline
\end{tabular}

bedtime containing either $1 \mathrm{~g}$ mesalazine (Pentasa) or placebo.

Patients were enrolled consecutively following a medical evaluation of the initial clinical and endoscopic severity of the condition using rectosigmoidoscopy or full colonoscopy. They were evaluated at inclusion, and at four and eight weeks using the UCDAI score, which is based on clinical signs and endoscopic evaluation of the distal colon during rectosigmoidoscopy. Briefly, the UCDAI score is the sum score of four parameters, each scoring between 0 and 3, making 12 the worst score: (a) stool frequency (0, normal; 1, 1-2.4 stools/ day more than normal; 2, 2.5-4 stools/day more than normal; $3,>4$ stools/day more than normal, based on the average of the last three days); (b) rectal bleeding (0, none; 1, traces of blood; 2, frank blood; 3, mainly blood, using the most severe bleeding episode within the last three days of a period); (c) mucosa appearance (based on sigmoidoscopy: 0, normal; 1, erythema, reduced capillary network, mild friability, minimal granularity; 2, friability, marked erythema, no vascularisation, erosions, pus; 3, ulceration, spontaneous bleeding, pus); and (d) the physician's global assessment (0, no active disease; 1, mild disease; 2, moderate disease; 3, severe disease). According to the sum score, UC activity was classified as follows ${ }^{17}$ : sum score 0-2 (none or light); 3-5 (mild); 6-8 (moderate); 9-12 (severe). Remission was defined as a UCDAI score $<2$. Improvement was defined as a decrease in the UCDAI score by $\geqslant 2$ points from baseline. Evaluation was also done at two weeks without endoscopic examination, and an abbreviated UCDAI based only on clinical signs was calculated at that date (not reported here).

Patients were asked to complete diaries daily with number of stools and rectal bleeding. Time to cessation of rectal bleeding was evaluated based on the diary records.

\section{End points}

All end points were defined when planning the study. The primary end point was remission rate at four weeks based on the UCDAI score. Secondary end points included remission rates at eight weeks; improvement rates at four and eight weeks; and time to cessation of rectal bleeding. Acceptability of using an oral/enema combination therapy was assessed at week 8; patients were asked if they would like to take a combination therapy in case of relapse. Safety assessment was based on adverse events and the following laboratory parameters which were assessed at four and eight weeks: serum creatinine, liver enzymes, platelets, white blood count and red blood count, and urinary tests for protein and haemoglobin.

\section{Sample size determination and statistical analyses}

Patients were assigned to intention to treat (ITT), per protocol (PP), and safety populations prior to unblinding of the data. The primary efficacy analysis was based on the ITT population. A supporting analysis on the course of the UCDAI score and related variables (that is, remission and improvement rate) was done on the PP population. Differences between treatment groups were analysed, applying the two sided $\chi^{2}$ test at a significance level of $\alpha=0.05$. Time to cessation of rectal bleeding (date of cessation-date of first drug intake) was analysed using the non-parametric KaplanMeier method.

The hypothesis was 30\% remission at four weeks in the oral treatment plus placebo enema group. Thus it was calculated that 186 completed patients were required to detect a difference in remission rate of at least $20 \%$, with $80 \%$ power and $\alpha=0.05$. Due to slow recruitment, the study was prolonged compared with the original plan. However, the study period was still insufficient to recruit the required number of patients. A total of 146 patients were screened and 127 patients were randomised. Of 127 randomised patients, 71 were allocated to the mesalazine enema group and 56 to the placebo enema group.

\section{RESULTS}

Demographic and baseline characteristics of the patients are shown in table 1 .

A total of $59(83 \%)$ and $47(84 \%)$ patients in the mesalazine enema and placebo enema groups, respectively, completed four weeks of treatment, and $58(82 \%)$ and 40 (71\%) patients completed eight weeks of treatment. Reasons for study termination are indicated in fig l. A total of 116

Table 3 Remission rates in the intention to treat (ITT) and per protocol (PP) populations

\begin{tabular}{|c|c|c|c|c|c|c|c|c|}
\hline & \multicolumn{4}{|c|}{ ITT population } & \multicolumn{4}{|c|}{ PP population } \\
\hline & $\begin{array}{l}\text { Total No } \\
\text { of patients }\end{array}$ & $\begin{array}{l}\text { Remission } \\
\text { rate (\%) }\end{array}$ & $95 \% \mathrm{Cl}$ & $p$ Value & $\begin{array}{l}\text { Total No } \\
\text { of patients }\end{array}$ & $\begin{array}{l}\text { Remission } \\
\text { rate (\%) }\end{array}$ & $95 \% \mathrm{Cl}$ & p Value \\
\hline \multicolumn{9}{|l|}{ Week 4} \\
\hline Mesalazine enema & 57 & 44 & $31 \%, 58 \%$ & \multirow{2}{*}{0.3079} & 41 & $46 \%$ & $31 \%, 63 \%$ & \multirow{2}{*}{0.4837} \\
\hline $\begin{array}{l}\text { Placebo enema } \\
\text { Week } 8\end{array}$ & 47 & 34 & $21 \%, 49 \%$ & & 29 & $38 \%$ & $21 \%, 58 \%$ & \\
\hline Mesalazine enema & 58 & 64 & $50 \%, 76 \%$ & \multirow{2}{*}{0.0298} & 42 & $67 \%$ & $50 \%, 80 \%$ & \multirow{2}{*}{0.0347} \\
\hline Placebo enema & 47 & 43 & $28 \%, 58 \%$ & & 29 & $41 \%$ & $24 \%, 61 \%$ & \\
\hline
\end{tabular}


Table 4 Cessation of rectal bleeding in the intention to treat population

\begin{tabular}{|c|c|c|c|c|c|}
\hline & \multicolumn{2}{|c|}{ Mesalazine enema } & \multicolumn{2}{|c|}{ Placebo enema } & \multirow[b]{2}{*}{$\begin{array}{l}\text { Log rank test } \\
\text { (p value) }\end{array}$} \\
\hline & $\begin{array}{l}\text { Bleeding at } \\
\text { baseline (n) }\end{array}$ & $\begin{array}{l}\text { Cessation of } \\
\text { bleeding } \\
\text { (n (\%)) }\end{array}$ & $\begin{array}{l}\text { Bleeding at } \\
\text { baseline (n) }\end{array}$ & $\begin{array}{l}\text { Cessation of } \\
\text { bleeding } \\
\text { (n (\%)) }\end{array}$ & \\
\hline Any rectal bleeding & 55 & 40 (73\%) & 40 & 15 (38\%) & 0.0025 \\
\hline Traces of blood & 18 & 11 (61\%) & 16 & $7(44 \%)$ & 0.4439 \\
\hline Frank blood & 31 & $25(81 \%)$ & 20 & $7(35 \%)$ & 0.0031 \\
\hline Mainly blood & 6 & $4(67 \%)$ & 4 & $1(25 \%)$ & 0.2324 \\
\hline
\end{tabular}

patients (63 in the mesalazine enema and 53 in the placebo enema group) constituted the ITT population (that is, patients who received the study drug at least once and who had at least one evaluation of efficacy after baseline). The PP population consisted of 71 patients (42 in the mesalazine enema and 29 in the placebo enema group-that is, patients without protocol violations who were likely to bias the assessment of the primary end point). The planned number of patients was not reached, as explained in the statistical analyses section.

\section{Treatment efficacy}

Remission and improvement rates were higher in the mesalazine enema group at both week 4 and week 8 compared with the placebo enema group (fig 2). In the ITT population the difference was significant for improvement both at four and eight weeks and for remission at eight weeks. Similar results were obtained in the PP population (tables 2, 3).

Compared with the placebo enema, time to cessation of rectal bleeding was significantly shorter for patients treated with the mesalazine enema who had any bleeding $(p=0.0025)$ or frank bleeding at baseline $(p=0.0031)$. Among patients with any rectal bleeding at baseline, bleeding ceased within the eight weeks of the study period in $73 \%$ of patients in the mesalazine enema group and in 38\% of patients in the placebo enema group. Among 51 patients with frank rectal bleeding at baseline, bleeding ceased within this period in $81 \%$ of patients in the mesalazine enema group and in $35 \%$ of patients in the placebo enema group (table 4 ). There was a similar pattern noted for cessation of bleeding at week 4 in the mesalazine enema group for patients with any rectal bleedings, traces of blood, frank blood, and mainly

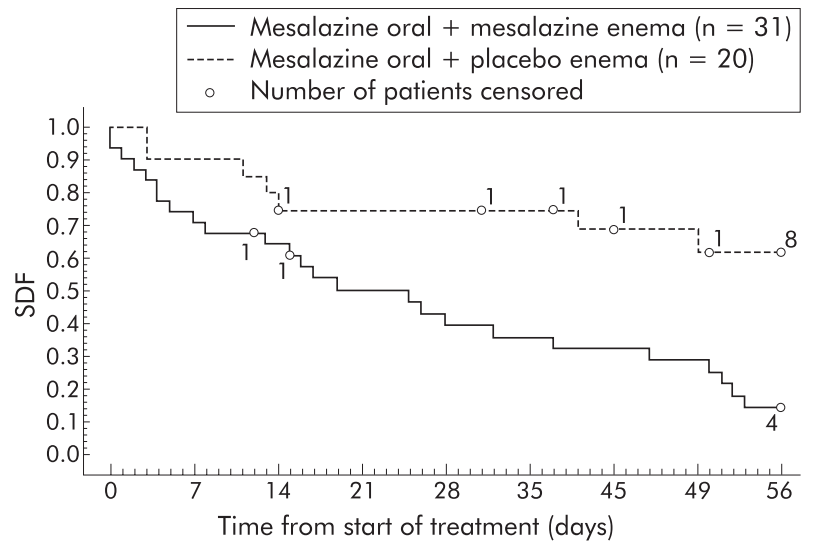

Figure 3 Time to cessation of rectal bleeding in patients with frank bleeding at baseline. SDF, survival distribution function from KaplanMeier survival analysis (proportion of patients with rectal bleeding). All patients without cessation of rectal bleeding by day 56 or who withdrew prematurely were censored. blood $(49 \%, 44 \%, 58 \%$, and $17 \%$ of patients, respectively, compared with $25 \%, 31 \%, 25 \%$, and $0 \%$, respectively, of patients in the placebo enema group stopped bleeding). Among patients with frank rectal bleeding at baseline, bleeding had ceased in 50\% treated with the mesalazine enema by day 21 whereas the majority of placebo enema patients continued to have rectal bleedings at day 56 (fig 3).

\section{Acceptability of combination therapy}

A total of $51 / 61$ patients (84\%) in the mesalazine enema and $45 / 53$ patients $(85 \%)$ in the placebo enema group were willing to take a combination therapy in the future.

\section{Adverse events}

During the course of the eight week study period, 24/71 patients $(34 \%)$ in the mesalazine enema group and $28 / 56$ patients $(50 \%)$ in the placebo enema group had at least one adverse event after the start of treatment. The majority of adverse events was of mild or moderate intensity. The most common adverse events considered drug related were diarrhoea (in $4 \%$ of patients), headache $(4 \%)$, and vomiting $(3 \%)$ in the mesalazine enema group. In the placebo enema group, the most common drug related adverse event was abdominal pain $(4 \%)$. Three patients $(4 \%)$ in the mesalazine enema group and one patient $(2 \%)$ in the placebo enema group had a serious adverse event, all afflicting the gastrointestinal system (aggravation of ulcerative colitis, painful defecation, vomiting, abdominal pain, and/or bloody diarrhoea) and all considered unrelated to the study drug. There were no deaths during the course of the study.

\section{Laboratory parameters}

There were no relevant changes during the study in serum creatinine, urinary protein or urinary haemoglobin, platelet count, white blood count, or red blood count, and were there no obvious differences between the treatment groups. Clinically significant increases in alanine aminotransferase or aspartate aminotransferase (defined as increases of more than twice baseline levels or more than four times the upper level of normal) were seen in one patient in the mesalazine enema group and in two patients in the placebo enema group. One patient (placebo enema group) was withdrawn from the study at week 4 due to an elevated gamma glutamyl transferase value.

\section{DISCUSSION}

Despite considerable progress in our knowledge and understanding of the disease, treatment of UC remains a challenge. ${ }^{1}$ Mesalazine has proven to be effective orally for extensive disease and locally (enemas, foams, or suppositories) in the treatment of distal forms of the disease. It has been established that the optimal dose of mesalazine is 3-4 g/ day for oral administration and $1 \mathrm{~g} /$ day for rectal administration. ${ }^{1247914}$ Prolonging the combination of oral $(2.4 \mathrm{~g})$ and rectal mesalazine $(2 \mathrm{~g}$ ) from four to eight weeks did not increase the remission rate. ${ }^{16}$ In order to further optimise the 
treatment, some authors examined combining rectal and oral administration in patients with distal colitis, and showed that this combined strategy was more effective than oral treatment alone. ${ }^{311}$ Our study is the first randomised controlled trial that assessed the efficacy of a combined strategy in patients with extensive UC.

The results obtained in this study for patients treated with $4 \mathrm{~g}$ oral mesalazine alone (plus placebo enema) are consistent with previous studies that demonstrated the efficacy of oral mesalazine for distal UC. ${ }^{241920}$ Adding a daily $1 \mathrm{~g}$ mesalazine enema in mild/moderate active extensive UC for the first four weeks of an eight week course of daily oral mesalazine $4 \mathrm{~g}$ resulted in significantly higher improvement rates at weeks 4 and 8 and significantly higher remission rates at week 8 . The primary end point (remission rate at week 4), although higher in the mesalazine enema group (44\% v 34\%), did not reach statistical significance.

A possible reason may be that more than four weeks are required for the healing process of the colonic mucosa. We arbitrarily chose remission at four weeks as our primary end point as there were no previous randomised controlled trials in this field, and we used strict criteria for remission (that is, a UCDAI of 0 or 1 ). In the study by Vecchi et $a$., there was no significant difference in the effects of $4 \mathrm{~g} 5$-ASA orally versus $2 \mathrm{~g}$ orally combined with $2 \mathrm{~g}$ as an enema in patients with ulcerative colitis but it is important to consider that this study included very few subjects with extensive colitis and that a very high rate of remission $(>80 \%)$ was reached in both groups. ${ }^{15}$ Furthermore, different oral doses of 5-ASA were used in this study while equal doses with or without 5-ASA rectally were used in our trial.

All included patients had either an established or a new diagnosis of extensive colitis. For practical reasons full colonoscopies were not requested throughout the study. As $100 \mathrm{ml}$ enemas usually only reach the splenic flexure, we cannot speculate on the evolution of lesions upstream. Using full colonoscopy to assess the results would have provided such data but we chose not to insist on this.

The expected number of patients included could not be reached within the study period, although extended by three months, because of considerable difficulties in recruiting patients in our Western European countries. Many patients with active extensive colitis met our exclusion criteria (for example, they were receiving treatment with high doses of salicylates, local treatments, oral steroids, or immunosuppressive agents). As UC is a chronic disorder, patients are used to rapidly adjusting their treatment when they have a flare up; sometimes they adapt it by themselves or on the advice of their general practitioners. Patients may have been reluctant to use a rectal enema for four weeks and undergo rectosigmoidoscopy three times within two months. These issues should be considered in the design of new studies in UC.

In general, our results showed that the combined strategy was more effective and safe. Addition of $1 \mathrm{~g}$ mesalazine/ $100 \mathrm{ml}$ enema (Pentasa) for the initial four weeks of an eight week oral therapy regimen with mesalazine $4 \mathrm{~g}$ /day (Pentasa $1 \mathrm{~g}$ sachets, twice daily dosing) resulted in improvement rates of $89 \%$ at four weeks and $86 \%$ at eight weeks compared with $62 \%$ and $68 \%$ in the standard treatment group. Rectal bleeding stopped in significantly more patients in the active enema group compared with the placebo group. Despite the higher mesalazine load of the oral/enema mesalazine combination, no concerns were raised with respect to the safety profile, and the combination treatment was highly accepted by patients.

Overall, this study has demonstrated the beneficial effects of adding a daily $1 \mathrm{~g}$ Pentasa enema for the initial four weeks during eight weeks of treatment with Pentasa $4 \mathrm{~g}$ orally. We believe that owing to the superiority of the combined approach, it should be used as a firstline treatment in patients with mild to moderate extensive UC.

In our view, this treatment may also be used in preference to steroids (which have more side effects) as secondline treatment if the disease is not severe, but this needs to be studied in a prospective randomised controlled trial.

\section{ACKNOWLEDGEMENTS}

We thanks all of the participating centres in the six countries for their involvement.

UK: Addenbrooke's Hospital, Dr Parkes; Bristol Royal Infirmary, Dr Probert; Conquest Hospital, Dr Rademaker; Cumberland Infirmary, Dr Burke; Northern General Hospital, Dr Riley; St Mark's Hospital, Dr Forbes; Ulster Hospital, Dr Tham. France: Agen, Dr Cazals; Béziers, Dr Dalbies; Castelnau le lez, Dr Pierrugues; Clermont-Ferrand, Dr Larpent; Grenoble, Pr Bonaz; Le Mans, Dr Blanchi; Montélimar, Dr Gompel; Nice, Pr Hebuterne; Nice, Dr Karsenty; Perpignan, Dr Bougnol; Toulouse, Dr Coulom; Sweden: Ersta Hospital, Stockholm, Henry Nyhlin; Huddinge Hospital, Stockholm, Mikael Lördal; Kärnsjukhuset, Skövde, Gunnar Midhagen; Karolinska Hospital, Stockholm, Ragnar Befrits; Länsjukhuset, Halmstad, Nils Werner; Länsjukhuset Ryhov, Jönköping, Christer Grännö; Sahlgrenska University Hospital Göteborg, Anders Kilander; Södersjukhuset, Stockholm, Per Karlén; S:t Görans Hospital, Dagny Ståhlberg; University Hospital MAS, Malmö, Stefan Lindgren. Germany: Berlin, Dr med Heinz-Jochen Kramm. Spain: Hospital Clínico de Valencia, Dr Benages; Hospital Clínico San Carlos, Dr García-Paredes; Hospital de Sagunto, Dr Hinojosa; Hospital de Santiago, Dr Lorenzo; Hospital do Meixoiero, Dr Pineda; Hospital Galdakao, Dr Cabriada; Hospital Germans Trias i Pujol, Dr Domenech; Hospital Gregorio Marañón, Dr Glez-Lara; Hospital Josep Trueta, Dr Glez-Huix; Hospital La Paz, Dr Fdez-Blanco; Hospital Mutua Tarrasa, Dr Esteve; Hospital Ramón y Cajal, Dr López San Román; Hospital Son Dureta, Dr Obrador. The Netherlands: Isala Klinieken, Zwolle, Dr Oudkerk Pool; St Streekziekenhuis Midden-Twente, Hengelo, Dr Tan.

Thanks to the medical writer, Dr Kristian Kunde, Parexel International, Berlin.

This study was sponsored by Ferring Pharmaceuticals.

\section{Authors' affiliations}

P Marteau, Hôpital Européen Georges Pompidou, Paris, France

C Probert, Clinical Sciences at South Bristol, Bristol Royal Infirmary, UK S Lindgren, University Hospital MAS, Malmoe, Sweden

M Gassul, Hospital Germans Trias i Pujol, Carretera de Canyet, s/n, Spain

G Tan, Regional Hospital Midden-Twente, Hengelo, the Netherlands A Dignass, Universitätsklinikum Charite, Campus Virchow-Klinikum, Berlin, Germany

R Befrits, Karolinska Hospital, Stockholm, Sweden

G Midhagen, Kärnsjukhuset, Skövde, Sweden

J Rademaker, Conquest Hospital, East Sussex, UK

M Foldager, Ferring Pharmaceuticals, Copenhagen, Denmark

Conflict of interest: None declared.

Pentasa is the registered trademark of Ferring BV or one of its affiliates

\section{REFERENCES}

1 Hanauer SB. Medical therapy for ulcerative colitis. Gastroenterology 2004; 126:1582-92.

2 Sutherland L, MacDonald JK. Oral 5-aminosalicylic acid for induction of remission in ulcerative colitis. Cochrane Database Syst Rev 2003;3:CD000543

3 D'Albasio G, Trallori G, Gavazzi O, et al. Combined therapy with 5aminosalicylic tablets and enemas for maintaining remission in ulcerative colitis. Ital J Gastroenterol 1991;23:12-14.

4 Hanaver SB, Schwartz J, Robinson M, et al. Mesalamine capsules for treatment of active ulcerative colitis. Am J Gastroenterol 1993;88:1 188-97.

5 Miner $\mathbf{P}$, Hanauer SB, Robinson M, et al. Safety and efficacy of controlledrelease mesalamine for maintenance of remission in ulcerative colitis. Dig Dis Sci 1995;40:296-304

6 Marshall JK, Irvine EJ. Putting rectal 5-aminosalicylic acid in its place: The role in distal ulcerative colitis. Am J Gastroenterol 2000:95:1628-36.

7 Cohen RD, Woseth DM, Thisted RA, et al. A meta-analysis and overview of the literature on treatment options for left-sided ulcerative colitis and ulcerative proctitis. Am J Gastroenterol 2000;95:1263-76. 
8 Safdi MA, Demicco MP, Sninsky CA, et al. A double-blind comparison of oral versus rectal mesalamine versus combination therapy in the treatment of distal ulcerative colitis. Am J Gastroenterol 1997;92:1867-71.

9 Campieri M, Gionchetti P, Belluzzi A, et al. Optimum dosage of 5aminosalicylic acid as rectal enemas in patients with active ulcerative colitis. Gut 1991;32:929-31.

10 Hanaver SB. Dose-ranging study of mesalamine (Pentasa) in the treatment of acute ulcerative proctosigmoiditis: Results of a multicentered placebocontrolled trial. Inflamm Bowel Dis, 1998;4:79-83.

11 Piodi LP, Ulivieri FM, Cermesoni L, et al. Long-term intermittent treatment with low-dose 5-aminosalicylic enemas is efficacious for remission maintenance in ulcerative colitis. Scand J Gastroenterol 2004;39:154-7.

12 Frieri G, Pimpo MT, Palumbo GC, et al. Rectal and colonic mesalazine concentration in ulcerative colitis: Oral vs. oral plus topical treatment. Aliment Pharmacol Ther 1999:13:1413-17.

13 Naganuma M, Iwao Y, Ogata $H$, et al. Measurement of colonic mucosal concentrations of 5-aminosalicylic acid is useful for estimating its therapeutic efficacy in distal ulcerative colitis: Comparison of orally administered mesalamine and sulfasalazine. Inflam Bowel Dis 2001;7:221-5.

14 Riley SA. What dose of 5-aminosalicylic acid (mesalazine) in ulcerative colitis? Gut 1998;42:761-3.
15 Vecchi M, Meucci G, Gionchetti P, et al. Oral versus combination mesalazine therapy in active ulcerative colitis: a double-blind, double-dummy, randomized multicentre study. Aliment Pharmacol Ther $2001 ; 15: 251-6$

16 Paoluzi P, D'Albasio G, Pera A, et al. Oral and topical 5-aminosalicylic acid (mesalazine) in inducing and maintaining remission in mild-moderate relapse of ulcerative colitis: one-year randomised multicentre trial. Dig Liver Dis 2002;34:787-93

17 Sutherland LR, Martin F, Greer S, et al. 5-Aminosalicylic acid enema in the treatment of distal ulcerative colitis, proctosigmoiditis, and proctitis. Gastroenterology 1987;92:1894-8

18 Farup PG, Hinterleitner TA, Lukas $M$, et al. Mesalazine $4 \mathrm{~g}$ daily given as prolonged-release granules twice daily and four times daily is at least as effective as prolonged-release tablets four times daily in patients with ulcerative colitis. Inflamm Bowel Dis 2001;7:237-42.

19 Schroeder KW, Tremaine WJ, Ilstrup DM. Coated oral 5-aminosalicylic acid therapy for mildly to moderately active ulcerative colitis. A randomized study. N Engl J Med 1987;317:1625-9.

20 Sninsky CA, Cort DH, Shanahan F, et al. Oral mesalamine (Asacol) for mildly to moderately active ulcerative colitis. A multicenter study. Ann Intern Med $1991 ; 115: 350-5$.

\section{EDITOR'S QUIZ: GI SNAPSHOT}

\section{An unusual cause of soft tissue infection}

\section{Clinical presentation}

A 68 year old diabetic was admitted with a history of vomiting and feeling unwell. He was found to be pyrexial and tachycardic. He had brawny discolouration of the skin in the right forearm and right leg. He was noted to have crepitus in the right forearm and right shin. No obvious external wounds could be seen. There was no history of trauma. His creatine phosphokinase was found to be elevated at $13220 \mathrm{IU} / \mathrm{l}$. He had radiographs of the right leg and forearm (figs 1,2). Later he became hypotensive and lost pulses in the right leg and left forearm. He was treated with antibiotics and intravenous fluids.

\section{Question}

What is the differential diagnosis? What emergency procedure would you perform?

See page 993 for answer

This case is submitted by:

M Thirumaran, B Altemimi, M Mohanraj
Dewsbury and District Hospital, Dewsbury, West Yorkshire, UK

Correspondence to: Dr M Thirumaran, 6, Broadcroft Way, Tingley, Wakefield, West Yorkshire WF3 1T, UK; thirumaranm@aol.com

doi: $10.1136 /$ gut.2004.053140
Robin Spiller, Editor

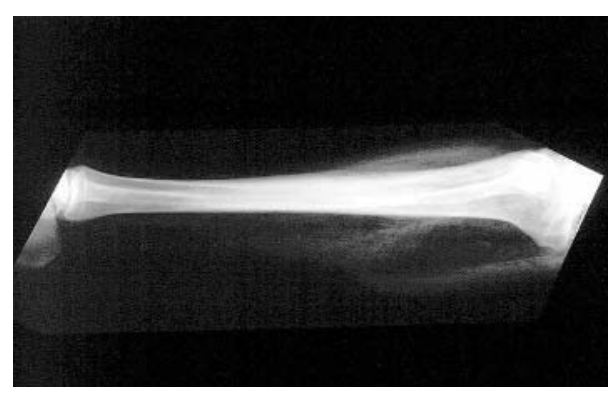

Figure 1 Radiograph of the right leg.

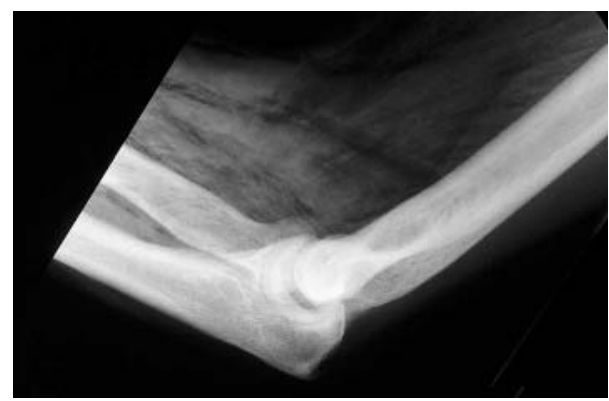

Figure 2 Radiograph of the right forearm. 